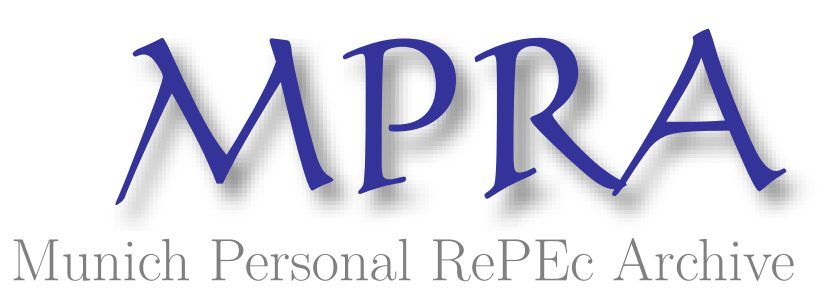

\title{
The political economics of redistribution, inequality and tax avoidance
}

Bethencourt, Carlos and Kunze, Lars

31 October 2013

Online at https://mpra.ub.uni-muenchen.de/51127/

MPRA Paper No. 51127, posted 01 Nov 2013 09:46 UTC 


\title{
The political economics of redistribution, inequality and tax avoidance
}

\author{
Carlos Bethencourt ${ }^{*, a, 1}$, Lars Kunze $\mathrm{b}^{\mathrm{b}, 1}$ \\ ${ }^{a}$ Universidad de La Laguna, Departamento de Economía, Campus de Guajara s/n, 38071 \\ Tenerife, Spain, phone: +34 922 317954, fax: +34 922 317204. \\ ${ }^{b}$ TU Dortmund, Department of Economics, 44221 Dortmund, Germany, phone: +49231 \\ 755-3275, fax: +49231 755-5404.
}

\begin{abstract}
A benchmark result in the political economy of taxation is that the degree of redistribution is positively linked to income inequality. However, empirical evidence supporting such a relationship turns out to be mixed. This paper shows how these different empirical reactions can be rationalized within a simple model of tax avoidance and costly tax enforcement. By focussing on structure induced equilibria in which taxpayers vote over the size of the income tax and the level of tax enforcement, we show that higher inequality may well decrease the extent of redistribution, depending on two opposing effects: the standard political effect and a negative tax base effect working through increases in the average level of tax avoidance and the share of enforcement expenditures in total tax revenue.
\end{abstract}

Keywords Tax avoidance, Voting, Redistribution

JEL-Classification D72, H31, H26

\section{Introduction}

A benchmark result in the political economy of taxation is that the extent of income redistribution rises if the mean to median income ratio increases (Meltzer and Richard, 1981). A substantial body of research builds upon this result. However, empirical evidence regarding the link between inequality and the extent of income redistribution remains inconclusive: whereas Meltzer and

\footnotetext{
${ }^{*}$ Corresponding author

Email addresses: cbethenc@ull.es (Carlos Bethencourt), lars.kunze@tu-dortmund.de (Lars Kunze)
}

Preprint submitted to Elsevier

October 31, 2013 
Richard (1983) find evidence in favor of a negative relation between the mean to median income ratio and redistribution, the findings of more recent studies point to the opposite (Rodriguez, 1999; Kenworthy and McCall, 2008; Georgiadis and Manning, 2012). According to these studies, a rise in income skewness is often accompanied by a cut-back in the welfare state. ${ }^{1}$ The aim of this paper is to rationalize these opposing findings within a simple model of tax avoidance and costly tax enforcement.

Both legal tax avoidance and the costs of taxation are economically significant. According to Slemrod (2007), the US income tax gap amounts to more than $15 \%$ of the estimated actual (paid plus unpaid) tax liability. Similarly, for Germany, the revenue loss equals one third of all income taxes actually paid (Lang et al., 1997). Regarding the costs of taxation, Evans (2003) notes that taxpayers's compliance costs are typically somewhere between $2 \%$ and $10 \%$ of total revenue while administrative costs are around $1 \%$ of total revenue. ${ }^{2}$ Besides the economic significance, the relevance of tax avoidance for the political problem has recently been emphasized by Roine (2006) and Traxler (2012). ${ }^{3}$ Specifically, when it comes to redistributive taxation, the presence of tax avoidance may not only give rise to atypical coalitions supporting higher taxes ('ends against the middle') but it will also affect the welfare properties of the voting outcome. However, none of these papers explicitly addresses the relation between inequality and redistribution in the context of tax avoidance. Furthermore, the costs of taxation and enforcement have mostly been neglected in these models. ${ }^{4}$ To close these gaps in the literature is the aim of the present paper.

We set up a simple model of tax avoidance in the spirit of Slemrod (1994). Individuals decide on costly and riskless activities that minimize their tax liability. Examples of such activities might be shifting of income into untaxed fringe benefits, into preferentially-taxed capital gains, or into the future, e.g., via pension plans (Slemrod and Yitzhaki, 2002). The particularity of the present model is twofold. First, we explicitly account for the costs of tax enforcement. Second, and in contrast to most of the existing literature, we study majority

\footnotetext{
${ }^{1} \mathrm{~A}$ prominent example is the first Reagan tax cut which decreased income taxes at a time when the mean-to-median income ratio was rising steadily.

${ }^{2}$ See also Sandford et al. (1989), Slemrod (1990) and OECD (2013) who highlight the economic significance of these costs relative to other public costs.

${ }^{3}$ See also Borck (2004), Borck (2009) and Traxler (2009) for models with illegal tax evasion instead of legal avoidance.

${ }^{4}$ See Traxler (2012) for an exception. His analysis, however, focusses on the welfare implications when there is sequential majority voting over enforcement and taxes.
} 
voting over a linear income tax schedule and the level of tax enforcement when avoidance is endogenous. Hence, the voting space is two-dimensional implying that the existence of a Condorcet winner of the majority voting game is not guaranteed. To deal with this characteristic of the game, we make use of the concept of structure induced equilibria (Shepsle, 1979).

The model allows us to explain the opposing empirical findings on the Meltzer-Richard hypothesis. Specifically, we show that for a given level of tax enforcement, the degree of income redistribution increases with inequality in line with the predictions of the standard model. However, endogenizing the level of tax enforcement introduces an additional effect through changes in the tax base which tends to decrease redistribution: if inequality leads to an increase in the mass of voters with low income abilities and voting for higher tax rates, the tax-base will decrease as average tax avoidance increases. Also, the share of enforcement expenditures in total tax revenue rises as low income taxpayers vote for a higher level of tax enforcement to increase the effectiveness of the new tax rate. However, since tax enforcement is costly, the amount of redistribution that could be financed with the same income tax rate will be smaller. Such a negative relationship between income inequality and the tax base is supported by recent empirical evidence: Aizenman and Jinjarak (2012) find that an increase in the Gini coefficient of inequality by 1 (in a scale of 0-100), is associated with a lower tax base of $2 \%$ of GDP. Similarly, using a panel of 17 OECD countries between 1975 and 2005, Milasi (2013) reports evidence of a negative relationship between the concentration of income at the top and budget revenues. The (standard) political effect and the tax-base effect thus have opposite signs. Redistribution would decrease as a consequence of higher inequality if, and only if, the tax-base effect dominates the political effect. This, in turn, depends on the sensitivity of public and private costs of taxation to the enforcement level.

Our work relates to simple majority voting models that are widely used to capture political feedback effects, see e.g. Alesina and Rodrik (1994) and Persson and Tabellini (1994) who argue that inequality depresses growth because anticipated redistributive taxation reduces the incentive to accumulate capital. Due to the mixed empirical evidence on the Meltzer-Richard hypothesis, however, some studies have advocated the use of more sophisticated models of redistribution based on the behavior of politicians or special interest groups (Gouveia and Masia, 1998). By contrast, this paper shows that the implications of simple majority voting models are not necessarily rejected by the empirical evidence described above. Similar conclusions have recently been reached by 
Bredemeier (2013) and DeFreitas (2012). However, the explanations of these papers differ from ours: while Bredemeier (2013) proposes a standard majorityvoting model with imperfect information ${ }^{5}$, DeFreitas (2012) studies the tax mix between direct and indirect taxes when individuals may evade taxation by supplying labour to an informal sector. ${ }^{6}$ In contrast to these studies, the present paper provides a complementary explanation based on behavioral responses and politico-economic consequences of tax avoidance and enforcement.

Our work also relates to the literature analyzing the effects of tax avoidance on income redistribution and the efficiency properties of majority voting outcomes over a linear income tax schedule, see Roine (2006) and Traxler (2012). Our contribution relative to these papers lies in extending the majoritarian voting game to a bidimensional issue space such that individuals do not only vote over the tax schedule but also over the level of tax enforcement. Hence, the focus of this paper is on structure induced equilibria which have, for example, been studied by Conde-Ruiz and Galasso (2003), Conde-Ruiz and Galasso (2005) and Bethencourt and Galasso (2008) in the context of inter- and intragenerational redistributive programmes such as social security, early retirement or public health. Our model complements these papers by modeling the role of tax avoidance and enforcement and its determinants in politico-economic equilibrium. In particular, our analysis explicitly accounts for the costs of taxation and tax enforcement, an issues that has mostly been neglected in theoretical analysis.

An empirical application reveals that our model can explain why two major US tax reforms, the Reagan tax cut in 1981 and the Clinton tax increase in 1993, have opposite signs even though income inequality has been steadily increasing in the late 70s as well as in the early 90s. More precisely, we suggest that the Tax Reform Act of 1986 (TRA) substantially improved the effectiveness of tax enforcement which in turn broadened the tax base and thus strengthened political support for higher tax rates and higher levels of enforcement.

The remainder of the paper is structured as follows. Section 2 describes the model. Section 3 sets up the voting game and Section 4 solves for the politicoeconomic equilibrium and analyzes its properties. Section 5 provides empirical

\footnotetext{
${ }^{5}$ Specifically, if an agent's preferred income tax rate depends on the perception of average rather than actual productivity, changes in income affect the income distribution by shifting voting power through income misperceptions in the voting game.

${ }^{6}$ Her findings, which are based on numerical simulations, point to a non-monotonic relationship between inequality and redistribution.
} 
evidence to support the theoretical results of our model and Section 6 concludes. All proofs are in the Appendix.

\section{The economy}

Consider an economy that is populated by a mass- 1 continuum of taxpayers with utility $U(c), U^{\prime}>0>U^{\prime \prime}$, where $c$ denotes consumption. Each taxpayer has an exogenous income, $y$, distributed on the support $[\underline{y}, \bar{y}] \in \Re_{+}$according to a cumulative density function (cdf) $F(y)$ with mean $\widetilde{y}$.

The government redistributes income equally among the total population through a constant income transfer which is financed through a linear personal income tax $\tau$. However, taxpayers can reduce their tax liability by engaging in costly activities. The government knows the existence of those activities and uses a portion of the tax collection to deter tax avoidance by financing a certain level of tax enforcement, $e$, which subsumes any costly activities that broaden the tax base. Thus, the (non-tax-deductible) costs for avoiding taxes are given by $K(a, e, y)$ which depend on the amount of evaded taxes $a$, on individual income $y$ and on the government's level of tax enforcement $e$. Following Traxler (2012), avoidance costs are increasing and strictly convex in $a$ and $e$. Furthermore, we assume that higher income makes avoidance less costly and therefore more attractive at the margin, i.e. $K_{a y}<0$ (Slemrod, 2001). ${ }^{7}$ Specifically, in order to obtain closed-form solutions, we consider a generalization of the standard functional form developed by Slemrod (1994): ${ }^{8}$

$$
K(a, e, y)=\kappa\left(\frac{a^{1+\gamma} e^{1+\delta}}{y^{\gamma}}\right)
$$

with $\kappa>0, \gamma>0, \delta>0$. A taxpayer's budget constraint is thus

$$
c=y-\tau(y-a)-\kappa\left(\frac{a^{1+\gamma} e^{1+\delta}}{y^{\gamma}}\right)+g
$$

\footnotetext{
${ }^{7}$ Since wealthy individuals have a lot of disposable income that is not needed to satisfy primary needs, they can invest it in activities leading to a reduction in their tax liabilities (such as pension plans, schemes that are aimed at allowing businesses to thrive. etc.). Gravelle (2013), e.g., argues that one of the main sources of international tax avoidance comes from the wealthy individual investors who set up secret bank accounts in tax haven countries. The reason is that high income individuals can afford to better information and tax consultants to avoid taxes more easily and successfully. Furthermore, the common conjecture that higherincome receivers have access to more tax avoidance strategies is supported by the evidence in Lang et al. (1997).

${ }^{8}$ See also Slemrod (2001) for similar specifications.
} 
where $g$ denotes a lump-sum transfer.

Optimal avoidance $a$ is characterized by

$$
a=\left(\frac{\tau}{\kappa(1+\gamma) e^{1+\delta}}\right)^{1 / \gamma} y
$$

which is increasing in the income level $y$ and the tax rate $\tau$ and decreasing in the enforcement level $e$.

The budget-balancing transfer is given by tax revenues net of enforcement costs

$$
g=\tau \int_{\underline{y}}^{\bar{y}}(y-a) d F-\phi(e)
$$

where $\phi(e)$ denotes the amount of public revenues that the government needs to provide a tax enforcement level $e$. Following Sandmo (1981), we assume $\phi^{\prime}>0$ and $\phi^{\prime \prime}>0 .{ }^{9}$ Specifically, we use the following simple functional form: $\phi(e)=\frac{e^{1+\eta}}{1+\eta}$, where $\eta>0$. Therefore,

$$
g=\tau \widetilde{y}\left(1-\left(\frac{\tau}{\kappa(1+\gamma) e^{1+\delta}}\right)^{1 / \gamma}\right)-\frac{e^{1+\eta}}{1+\eta}
$$

Taxpayers' preference relations over taxes and enforcement expenditures are characterized by their indirect utility function:

$$
\begin{array}{r}
V(\tau, e)=U\left(y\left[1-\left(\frac{1}{\kappa e^{1+\delta}}\right)^{1 / \gamma}\left(\frac{\tau}{1+\gamma}\right)^{(1+\gamma) / \gamma}\right]\right. \\
\left.+\tau(\widetilde{y}-y)\left[1-\left(\frac{\tau}{\kappa(1+\gamma) e^{1+\delta}}\right)^{1 / \gamma}\right]-\frac{e^{1+\eta}}{1+\eta}\right)
\end{array}
$$

\section{The voting game}

The personal income tax rate $\tau$ and the level of tax enforcement $e$ are decided by the agents through a political system of majoritarian voting. Each individual casts a ballot over $\tau$ and $e$. Individual preferences over the two issues are represented by the indirect utility function at Eq. (6). Notice that every agent has zero mass, and thus no individual vote could change the outcome of the election. Hence, we assume that individuals vote sincerely. The important

\footnotetext{
${ }^{9}$ The assumption that the government incurs convex costs in order to ensure a certain level of tax enforcement is in line with the literature on optimal taxation, see also Slemrod and Yitzhaki (1987).
} 
characteristic of this majoritarian voting game is that the issue space is bidimensional, $(\tau, e)$, and thus a Nash equilibrium may fail to exist. To deal with this feature, we analyze structure induced equilibria, due to Shepsle (1979), which reduces the game to a static issue-by-issue voting game.

To characterize the equilibria of this voting game, we apply the result in Shepsle (1979) [Theorem 3.1] to obtain sufficient conditions for a (structure induced) equilibrium to exist. In particular, if preferences are single-peaked along every dimension of the issue space, a sufficient condition for $\left(\tau^{*}, e^{*}\right)$ to be an equilibrium of the voting game is that $\tau^{*}$ represents the outcome of a majority voting over the jurisdiction $\tau$, when the other dimension is fixed at its level $e^{*}$, and viceversa. ${ }^{10}$

Thus, to apply Shepsle (1979)'s theorem to our environment, we need to ensure that individuals' preferences are single peaked along the two dimensions, $\tau$ and $e$. The following lemma describes a set of sufficient conditions.

Lemma 1. If $y<\left(\frac{1+\gamma}{\gamma}\right) \widetilde{y}$, then individuals' preferences are single peaked over $\tau$ for given e and over e for given $\tau$.

We therefore restrict the support of income type of individuals, in order to have that $y \in\left(\underline{y},\left(\frac{1+\gamma}{\gamma}\right) \widetilde{y}\right){ }^{11}$

\section{Politico-economic equilibria}

In this section, individual votes over each dimension of the issue space, $\tau$ and $e$, are examined issue-by-issue. Voters cast a ballot over $\tau$, for a given level of $e$, and viceversa. For each dimension, $\tau$ and $e$, votes are then ordered to identify the median vote, which, by Shepsle (1979)'s theorem, represents the structure induced equilibrium outcome of the voting game.

\subsection{Voting on the tax rate and the enforcement level}

Consider first voting over the personal income tax rate. For a given level of enforcement, $e$, a taxpayer with income $y$ would choose her most preferred

\footnotetext{
${ }^{10}$ See Persson and Tabellini (2000) for a simple explanation of how to calculate a structure induced equilibrium.

${ }^{11}$ Note that we could equivalently put some mild restrictions on $\gamma$. Furthermore, for $y \geq$ $\left(\frac{1+\gamma}{\gamma}\right) \tilde{y}$, it can be shown that indirect utility is monotonically decreasing in $\tau$ which in turn implies that rich individuals will always prefer zero taxation and hence no enforcement.
} 
income tax rate $\tau(e)$ by maximizing her indirect utility (see Eq. (6)) with respect to $\tau$. The next lemma characterizes the outcome of this vote.

Lemma 2. The most preferred tax rate by any type-y individual is

$$
\tau(e)=\max \left\{0, \kappa(1+\gamma) e^{1+\delta}\left(\frac{\widetilde{y}-y}{\left(\frac{1+\gamma}{\gamma}\right) \widetilde{y}-y}\right)^{\gamma}\right\}
$$

The preferred tax rate is decreasing in $y$, i.e. $\frac{\partial \tau(e)}{\partial y}<0$ and increasing in e, i.e. $\frac{\partial \tau(e)}{\partial e}>0$.

Lemma 2 states that richer individuals, $y>\widetilde{y}$ vote for zero taxes, whereas poorer individuals, $y<\widetilde{y}$, vote for positive tax rates. This finding resembles the well known fact that a progressive redistributive transfer program characterized by flat transfers and a linear income tax hurts relatively richer individuals. In the present model, however, tax avoidance decreases the effective contributions and, as high income agents have lower costs of avoidance, this reduction will be larger for richer than for poorer taxpayers, thereby reducing the progressiveness of the system. As a result, some rich individuals might become net beneficiaries of the system and have incentives to vote for positive taxes. However, as the marginal cost of avoidance is positive, this cost is larger for richer taxpayers with high levels of avoidance, which in turn reduces their interest in the redistributive program. Thus, when a taxpayer casts a ballot over the program he not only takes into account the effective contribution but also the cost of avoidance.

The total effective cost incurred by a taxpayer, $\mathbb{C}$, equals the effective contribution plus the cost of avoidance ${ }^{12}$, i.e.,

$$
\mathbb{C}=\tau(y-a)+K=\tau y\left(1-\left(\frac{\gamma}{1+\gamma}\right)\left(\frac{\tau}{\kappa(1+\gamma) e^{1+\delta}}\right)^{1 / \gamma}\right)
$$

with

$$
\frac{\partial \mathbb{C}}{\partial \tau}=y\left(1-\left(\frac{\tau}{\kappa(1+\gamma) e^{1+\delta}}\right)^{1 / \gamma}\right)=y-a \geq 0 \text { and } \frac{\partial\left(\frac{\partial \mathbb{C}}{\partial \tau}\right)}{\partial y}>0
$$

\footnotetext{
${ }^{12}$ Note that if there was no tax avoidance, the total cost of paying taxes would equal the contribution to the transfer program (the statutory contribution), $\tau y$. If the amount of tax avoidance is positive, however, the cost of paying taxes, $\mathbb{C}$, is lower than the the statutory contribution, $\mathbb{C}<\tau y$, indicating that tax avoidance is indeed a profitable activity.
} 
The effective cost of paying taxes increases with the tax rate and, more importantly, the marginal cost is higher for richer than for poorer taxpayers. Therefore, richer taxpayers suffer relatively higher effective costs of paying taxes, and so, they always vote for zero tax rates. In other words, the gain of lower contributions to the redistributive program due to tax avoidance is offset by an increase in the marginal cost of avoidance, thereby leaving the progressiveness of the tax system unchanged.

Finally, an increase in the level of tax enforcement has two opposing effects: the reduction in the size of the redistributive program due to a smaller share of public revenues devoted to finance income transfers must be balanced with a positive effect on public revenues through a decrease in the level of tax avoidance. As the net effect turns out to be positive, taxpayers' incentives to vote for higher tax rates increase.

It is now straightforward, for a given level of tax enforcement, to order every agent's vote over the size of the redistributive program and to identify the median voter's type. Agents can be ranked according to their type, with low-income taxpayers choosing larger sizes. The median voter is the type- $y_{m \tau}$ taxpayer who divides the electorate in halves. For a given level of enforcement, $e$, we identify her most preferred tax rate as $\tau_{m \tau}(e)$.

Next, consider voting over the level of tax enforcement. The level of tax enforcement chosen by a type $y$ taxpayer, given a personal income tax rate $\tau$, is characterized by the following lemma:

Lemma 3. The most preferred enforcement level by any type-y individual is

$$
e(\tau)=\left[\left(\frac{1+\delta}{1+\gamma}\right)\left(\frac{\tau^{1+\gamma}}{\kappa(1+\gamma)}\right)^{1 / \gamma}\left(\left(\frac{1+\gamma}{\gamma}\right) \widetilde{y}-y\right)\right]^{\frac{\gamma}{1+\gamma(1+\eta)+\delta}}
$$

The preferred enforcement level is decreasing in $y$, i.e. $\frac{\partial e(\tau)}{\partial y}<0$ and increasing in $\tau$, i.e. $\frac{\partial e(\tau)}{\partial \tau}>0$.

Lemma 3 establishes that each taxpayer is interested in supporting a positive level of tax enforcement. To understand this result, consider the different ways of how tax enforcement affects the redistributive program: on the one hand, a higher level of tax enforcement increases public costs and thus lowers the portion of revenues devoted to income transfers. On the other hand, however, stricter enforcement reduces tax avoidance which in turn increases public 
revenues. In order to see which effect prevails, we maximize the total amount of public revenues net of enforcement costs (Eq. 5) with respect to $e$

$$
\widehat{e}: \arg \max _{e} g ; \quad \widehat{e}=\left[\left(\frac{1+\delta}{1+\gamma}\right)\left(\frac{\tau^{1+\gamma}}{\kappa(1+\gamma)}\right)^{1 / \gamma}\left(\frac{1+\gamma}{\gamma}\right) \widetilde{y}\right]^{\frac{\gamma}{1+\gamma(1+\eta)+\delta}}
$$

which implies (by comparing equations (8) and (9)) that the net effect of tax enforcement on public revenues is positive. Consequently, taxpayers have an incentives to support a positive level of tax enforcement. ${ }^{13}$

Furthermore, Lemma 3 states that the preferred enforcement level is decreasing with taxpayers' income. The reason is that a higher level of enforcement increases the marginal cost of avoidance and thus lowers the total amount of avoided taxes. As this latter effect is more pronounced for richer taxpayers, the resulting increase in the effective contribution is also relatively larger for these individuals. Therefore, high income individuals suffer from a larger increase in the total effective cost of paying taxes, i.e.

$$
\frac{\partial \mathbb{C}}{\partial e}=\frac{(1+\delta)}{\gamma e}\left(\frac{\tau}{\kappa(1+\gamma) e^{1+\delta}}\right)^{1 / \gamma} y=\frac{(1+\delta)}{\gamma} \frac{a}{e} \geq 0 \text { and } \frac{\partial\left(\frac{\partial \mathbb{C}}{\partial e}\right)}{\partial y}>0
$$

and thus vote for a lower level of tax enforcement.

Finally, a higher tax rate not only increases public revenues and hence the total amount available to distribute between transfers and enforcement expenditures but also the incentives to avoid taxes which tends to decrease public revenues. Given that the first effect dominates ${ }^{14}$, taxpayers decide to devote a portion of the increase in public revenues to enhance the level of tax enforcement with the objective of reducing the higher level of tax avoidance and thus to expand the level of public revenues even further.

\footnotetext{
${ }^{13}$ Since taxpayers are the contributors to the program, however, they will not support the revenue maximizing level of tax enforcement. In fact, $e(\tau)<\widehat{e} \forall y$.

${ }^{14}$ We can define

$$
\begin{aligned}
& \widehat{\tau} \quad: \quad \arg \max _{\tau} \Omega=\tau \widetilde{y}\left(1-\left(\frac{\tau}{\kappa(1+\gamma) e^{1+\delta}}\right)^{1 / \gamma}\right) \\
& \widehat{\tau} \quad=\kappa(1+\gamma) e^{1+\delta}\left(\frac{1}{\left(\frac{1+\gamma}{\gamma}\right)}\right)^{\gamma}
\end{aligned}
$$

which implies that public revenue is increasing the size of the tax rate up to the level $\widehat{\tau}$ and consequently, the positive direct effect of a higher tax rate on public revenues overcomes the negative effect due to the increase in the tax avoidance.
} 
Following the previous lemma, we can now order the votes on the enforcement level according to the voters' types. The median voter is the low-income type- $y_{m e}$, who divides the electorate in halves. For a given size of the transfer program, $\tau$, we identify her most preferred level of tax enforcement as $e_{m e}(\tau)$. As the size of the votes for both variables is monotonic in income, the median voter's type is the same in both dimensions, i.e. $y_{m e}=y_{m \tau}=y_{m}$ and thus $\tau_{m \tau}(e)=\tau_{m}(e)$ and $e_{m e}(\tau)=e_{m}(\tau)$.

\subsection{Characterization of Politico-economic Equilibria}

Since preferences are single peaked, we can now apply Shepsle (1979)'s result, and characterize the structure induced equilibria:

Proposition 1. There exists a structure induced equilibrium, $\left(\tau^{*}, e^{*}\right)$, of the voting game, such that:

(A) $\quad\left(\tau^{*}=0, e^{*}=0\right)$ if $y_{m}>\widetilde{y}$;

(B) $\quad\left(\tau^{*}=\left(\left(m_{1} m_{2}^{\frac{1}{\gamma}}\right)^{(1+\delta)} m_{2}^{1+\eta}\right)^{\frac{1}{\eta-\delta}}, e^{*}=\left(m_{1} m_{2}^{\frac{1+\gamma}{\gamma}}\right)^{\frac{1}{\eta-\delta}}\right)$ if $y_{m}<\widetilde{y}$

with

$$
\begin{aligned}
& m_{1}=\left(\frac{1+\delta}{1+\gamma}\right)\left(\frac{1}{\kappa(1+\gamma)}\right)^{1 / \gamma}\left(\left(\frac{1+\gamma}{\gamma}\right) \widetilde{y}-y_{m}\right) \\
& m_{2}=\kappa(1+\gamma)\left(\frac{\widetilde{y}-y_{m}}{\left(\frac{1+\gamma}{\gamma}\right) \widetilde{y}-y_{m}}\right)^{\gamma}
\end{aligned}
$$

No redistributive program will exist if the median voter is a high-income taxpayer (case A). In this case, the level of tax enforcement will be zero as the median voter is not willing to support the system. If, however, a poorer median voter appears, then a redistributive program with a positive level of enforcement will exist (case B). ${ }^{15}$ In the following, we concentrate on the latter, empirically relevant case.

\footnotetext{
${ }^{15}$ Note that the existence of an interior equilibrium further requires $\delta \neq \eta$ which we assume to hold throughout the remaining analysis.
} 
We now proceed to analyze how the type of the median voter affects to the size of both the tax rate of the redistributive program and the enforcement level.

Proposition 2. For a structure induced equilibrium, $\left(\tau^{*}, e^{*}\right)$, of the voting game, an increase in the income inequality (a decrease in the type of the median voter, $\left.y_{m}\right)$ generates a new equilibrium, $\left(\tau^{* *}, e^{* *}\right)$, with two possible results:

(i) Lower redistribution: $\quad \tau^{* *}<\tau^{*}$ and $e^{* *}<e^{*} \Leftrightarrow \delta>\eta$

(ii) Higher redistribution : $\quad \tau^{* *}>\tau^{*}$ and $e^{* *}>e^{*} \Leftrightarrow \delta<\eta$

When inequality increases and $y_{m}$ declines, the tax rate and the tax enforcement level may increase or decrease depending exclusively on the relative strength of the cost parameters. We label the two cases Lower redistribution (LR) and Higher redistribution (HR), respectively. There are several offsetting effects: first, the new median voter at $\tau$-dimension decides to vote for a higher tax rate since the effective cost of paying taxes decreases for poorer taxpayers (see Lemma 2). This is the standard political effect implying a larger extent of redistribution and, as a consequence, a higher level of tax avoidance. Second, the poorer median voter at $e$-dimension chooses a higher level of tax enforcement in order to reduce the level of tax avoidance (see Lemma 3). However, as tax enforcement is costly, a higher level of tax enforcement requires more public resources and, as a consequence, the amount of redistribution that could be financed with the same income tax rate will be smaller. This negative tax-base effect reduces the incentive of the poorer median voter to support higher tax rates. Furthermore, a lower tax rate decreases the level of tax enforcement (according to Lemma 3). As a result, these indirect effects are running counter to the direct effects and the net effect on the tax rate and tax enforcement is ambiguous. ${ }^{16}$ Results will depend on the technology of producing tax enforcement,

\footnotetext{
${ }^{16}$ In fact, it is easy to prove that the net effect on the aggregate level of tax avoidance resulting from an increase in income inequality turns out to be positive: let $\widetilde{a}$ be the aggregate amount of tax avoidance

$$
\widetilde{a}=\left(\frac{\tau}{\kappa(1+\gamma) e^{1+\delta}}\right)^{1 / \gamma} \widetilde{y}
$$

In equilibrium, we have

$$
\widetilde{a}^{*}=\left(\frac{m_{2}}{\kappa(1+\gamma)}\right)^{1 / \gamma} \widetilde{y}=\left(\frac{\widetilde{y}-y_{m}}{\left(\frac{1+\gamma}{\gamma}\right) \widetilde{y}-y_{m}}\right) \widetilde{y}
$$


$\eta$, and the efficiency of tax enforcement in controlling tax avoidance, $\delta$ :

- The lower $\eta$, the higher is the elasticity of tax enforcement with respect to the public costs of producing it. In this case, a reduction of the amount of resources devoted to tax enforcement (e.g. in order to increase the amount of resources devoted to redistribution) would imply a substantial decrease in the level of tax enforcement. As a result, the level of tax avoidance would increase dramatically, which in turn lowers the amount of disposable resources. Thus, maintaining a certain level of tax enforcement in controlling tax avoidance would require a considerable amount of available tax revenue, thereby reducing strongly the disposable amount of resources devoted to redistribution.

- The higher $\delta$, the higher is the elasticity of the level of tax avoidance with respect to the level of tax enforcement. In this case, a reduction of the amount of resources devoted to tax enforcement would imply a decrease in the enforcement level and thus a considerably increase in the level of tax avoidance. Consequently, maintaining a certain level of tax avoidance in this setting, would require a considerable amount of available tax revenue, which in turn substantially lowers the scope of income redistribution.

Therefore, low levels of $\eta$ and high levels of $\delta$ imply large sizes of the indirect effects, this is, a substantial decrease in the tax base.

Figure 1 provides a graphical illustration of our results. For both cases (LR) and (HR) we first plot the initial reaction functions of each political dimension, $\tau(e)$ and $e(\tau)$ (Eqs. (7) and (8), respectively). These reaction functions, in turn, determine the initial equilibrium, $\left(\tau^{*}, e^{*}\right)$. Furthermore, we calculate $\bar{\tau}(e)$, the inverse of reaction function $e(\tau)$, which is

$$
\bar{\tau}(e)=\left[\frac{1}{m_{1}}\right]^{\frac{\gamma}{1+\gamma}} e^{\frac{1+\gamma(1+\eta)+\delta}{1+\gamma}}
$$

with

$$
\frac{\partial \widetilde{a}^{*}}{\partial y_{m}}<0 .
$$

Thus, the positive effect of the tax rate on the aggregate level of tax avoidance outweighs the negative effect through an increase in the level of tax enforcement. 

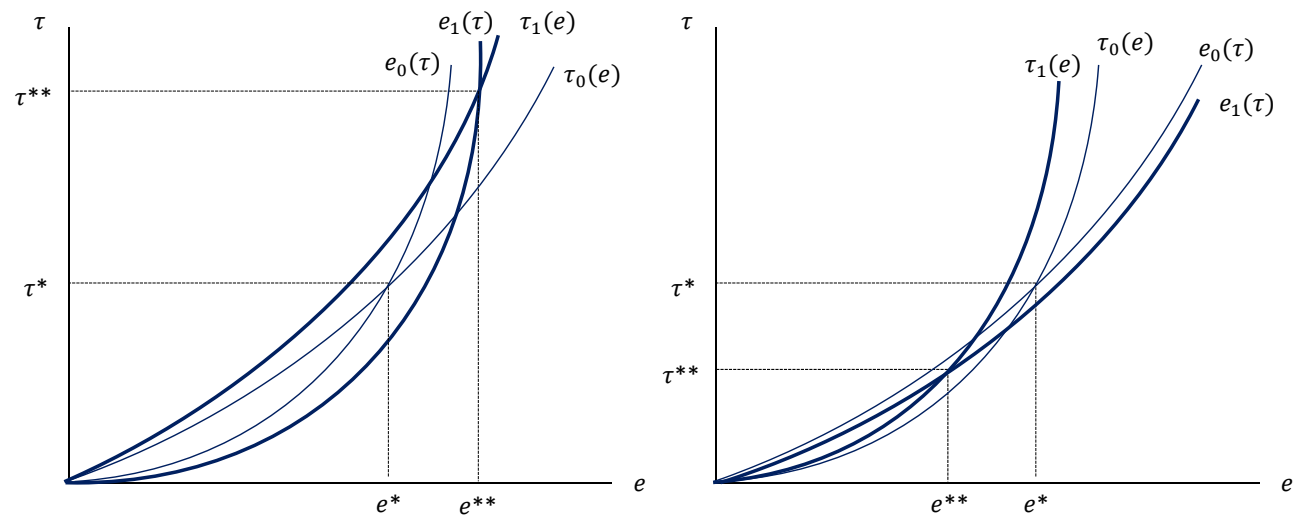

Figure 1: The effect of an increase in inequality; Cases HR (left) and LR (right).

To illustrate the existence of the two cases, we then determine the ratio of both reaction functions:

$$
\frac{\tau(e)}{\overline{\bar{\tau}(e)}}=\frac{m_{2} e^{1+\delta}}{\left[\frac{1}{m_{1}}\right]^{\frac{\gamma}{1+\gamma}} e^{\frac{1+\gamma(1+\eta)+\delta}{1+\gamma}}}=m_{2} m_{1}^{\frac{\gamma}{1+\gamma}} e^{\frac{\gamma(\delta-\eta)}{1+\gamma}}
$$

where

$$
\frac{\partial\left(\frac{\tau(e)}{\bar{\tau}(e)}\right)}{\partial e}=m_{2} m_{1}^{\frac{\gamma}{1+\gamma}} e^{\frac{\gamma(\delta-\eta)}{1+\gamma}-1} \frac{\gamma(\delta-\eta)}{1+\gamma}
$$

Therefore, we observe that this ratio is increasing or decreasing depending on the relative size of $\delta$ and $\eta$ :

$$
\begin{gathered}
\frac{\partial\left(\frac{\tau(e)}{\bar{\tau}(e)}\right)}{\partial e}>0 \Leftrightarrow \delta>\eta \Leftrightarrow \tau(e)>\bar{\tau}(e) \forall e>e^{*} \\
\frac{\partial\left(\frac{\tau(e)}{\bar{\tau}(e)}\right)}{\partial e}<0 \Leftrightarrow \delta<\eta \Leftrightarrow \tau(e)<\bar{\tau}(e) \forall e>e^{*}
\end{gathered}
$$

Once we have defined the two types of initial equilibria, it is easy to analyze the consequences of an increase in inequality (a decrease in $y_{m}$ ). In both cases, reaction function $\tau(e)$ moves to the left while reaction function $\bar{\tau}(e)$ moves to the right. These movement are the direct effects. However, in the left panel of Figure 1, we observe that the resulting new equilibrium $\left(\tau^{* *}, e^{* *}\right)$ implies higher levels of both tax rate and tax enforcement, case (HR), whereas in the right panel of Figure 1 we observe the opposite, case (LR).

Summarizing, the different reactions to a rise in the mean-to-median income ratio can be rationalized in a simple majority voting model with tax avoidance 
and costly tax enforcement. Thus, when generalized to a bidimensional issue space, i.e. voting over taxes and the level of enforcement, simple majorityvoting models of redistribution are not rejected by empirically observed negative relations between the mean-to-median income ratio and income taxation. In particular, our model highlights the importance of behavioral responses related to taxation and changes in the level of tax enforcement: if increases in income inequality are accompanied by an increase in tax avoidance activities, especially by rich individuals, poor individuals vote for higher levels of costly tax enforcement. These non-standard effects reduce the size of the redistributive income program and may thus cause the mean-to-median income ratio and redistribution to move in opposite directions, in contrast to the Meltzer-Richard hypothesis.

\section{Empirical application}

How do the predictions of our model relate to real-world observations? As has been emphasized by Bredemeier (2013), the first Reagan tax cut is a major anomaly to the Meltzer-Richard hypothesis. Shortly after the Reagan administration was elected in 1980, personal income taxes were reduced substantially in the Economic Recovery Tax Act (ERTA) of 1981. By contrast, the Omnibus Budget Reconciliation Act (OBRA) of 1993 seems to be consistent with the findings of Meltzer-Richard. Personal income taxes were increased shortly after the Clinton administration came into office in early 1993. Both tax reforms occurred at a time when the mean-to-median ratio of the US pre-tax income distribution has been rising steadily (see, e.g., Rodriguez (1999) or Esteban et al. (2007)).

In this section, we analyze whether the predictions of our model can help explaining the opposing outcomes of the tax reforms. Clearly, confronting the model with data is difficult as there are no direct estimates of the tax avoidance and cost parameters. Still, there are ways of comparing the model predictions with real-world observations.

As can be inferred from Figure 2, for example, the costs of tax collection (which can be interpreted as a proxy of the enforcement level $e$ ) steadily decreased from 0.55 cents in 1976 to 0.41 cents in 1981 . Over the same time period, the gross personal income tax gap increased from 22.0 to 60.1 billion dollars. Consequently, the increase in income inequality at the end of the 70 s and early 80s was accompanied by an increase in tax avoidance (and tax evasion), a lower 

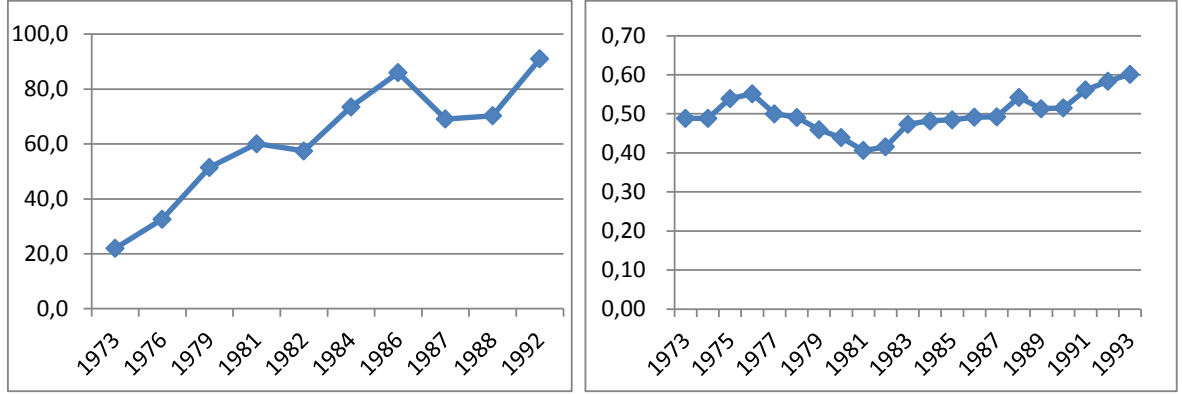

Figure 2: Gross individual income tax gap (in $\$$ billions) (left) and costs of collecting $\$ 100$ (right). Source: Internal Revenue Service - Tax Statistics (www.irs.gov/uac/Tax-Stats-2)

level of tax enforcement and a lower tax rate in line with the predictions of our model. More precisely, we have defined this outcome as the Lower redistribution (LR) case (see proposition 2). Considering the Clinton tax increase, however, we observe an increase in the costs of tax collections since the late 80s (from 0.49 cents in 1987 to 0.60 cents in 1993) as well as an increase in the tax gap (from 69.1 to 91.0 billion dollars). Therefore, in this second case, the increase in income inequality was accompanied by an increase in tax avoidance, a higher level of tax enforcement and a higher tax rate. We call this outcome the Higher redistribution (HR) case. As a result, according to our model, the tax base effect seemed to dominate in the early 1980s whereas the direct political effect was the predominant force in the early 1990s.

Our theory states that the existence of these two consecutive tax reforms with opposite effects in the tax rate and the enforcement level is related to changes in the relationship between the parameters $\eta$ and $\delta$. The main question is then whether there is (indirect) evidence on changes in the relative sizes of these parameters over time.

As has been noted in subsection 4.2 , the parameter $\eta$, for example, is inversely related to the elasticity of tax enforcement with respect to public costs of producing it. Thus, the lower the size of $\eta$, the higher the elasticity. This implies that a small amount of public revenues devoted to increase the enforcement level would have large effects. Consequently, we consider a low level of $\eta$ to be consistent with a tax system characterized by being not well organized, with poorly experienced officers, etc. In this type of tax systems with a low level of efficiency, there exist large opportunities to increase the enforcement level with relative low efforts. By contrast, when the tax system is well established, has 
reached a certain level of maturity, experience, organization, etc., more public resources devoted to increase tax enforcement should have a less pronounced effect. The idea is that the level of enforcement is already sufficiently high so that further increases would require a considerable amount of resources. Alternatively, if the amount of public revenues devoted to tax enforcement decreases, the level of tax enforcement decreases as well but relatively less than in the case in which the tax system is more inefficient.

Thus, the magnitude of $\eta$ is crucial to determine the type of equilibrium that results from voting on the tax rate and the enforcement level (see proposition 2). According to our model, the larger the size of $\eta$ and the lower the size of $\delta$, the lower is the tax-base effect, and so the resulting equilibrium would be characterized by higher tax rates and enforcement levels.

If we look at the recent history of the US tax system, we observe that, in fact, in the late 1980s, there was one major tax reform, the Tax Reform Act of 1986 (TRA), which drastically simplified the income tax code and broadened the tax base. As we have argued above, this improvement in the efficiency of the tax system can be interpreted as an increase in the parameter $\eta$. Such a change in the size of $\eta$, in turn, would explain why before the TRA, the Reagan's reform was characterized by a tax cut and a lower enforcement level but, after the TRA and its consequent improvement on the tax system efficiency and increase in the tax-base, the Clinton's tax reform was characterized by tax increase and a higher enforcement level.

Overall, the model thus seems to be consistent with real world observations, though, of course, our results should be interpreted with caution given the crudeness of the measures used.

\section{Conclusions}

A benchmark result of the political economy of taxation is that the meanto-median income ratio and the degree of income redistribution are positively linked. However, empirical evidence on this relationship remains inconclusive. Changes in the mean-to-median income ratio are often accompanied by developments in redistribution going in the opposite direction.

This paper has proposed a simple model of tax avoidance and costly enforcement to explain these different empirical findings. We have shown that increases in income inequality can lead to less redistribution. The key channel

for this non-standard result is a tax base effect that counteracts the standard 
mean-income effect. If taxpayers do not only vote over the size of the tax rate but also over the level of tax enforcement, higher taxes increase the average level of tax avoidance in the economy. This, in turn, decreases the tax base and therefore the amount of redistribution that could be financed by a given level of taxation. Due to this tax base effect, increases in income inequality can induce a negative relation between the mean-to-median income ratio and the degree of income redistribution. The overall effect, however, critically depends on the sensitivity of public and private costs of taxation to changes in the enforcement level.

Empirical evidence for the US lends support to our findings. In particular, our model is able to explain why two major tax reforms, the Reagan tax cut in 1981 and the Clinton tax increase in 1993, have opposite sings. We suggest that the efficiency gains of the tax system originating from the TRA in 1986 substantially improved the effectiveness of tax enforcement which in turn broadened the tax base and thus increased the amount of resources devoted to redistribution. As a consequence, political support for higher tax rates and higher levels of enforcements increased.

\section{Acknowledgements}

We thank Wolfram F. Richter and C. Bredemeier for helpful comments and suggestions. Any remaining errors are ours.

\section{References}

Aizenman, J., Jinjarak, Y., 2012. Income inequality, tax base and sovereign spreads. FinanzArchiv: Public Finance Analysis 68, 431-444.

Alesina, A., Rodrik, D., 1994. Distributive politics and economic growth. The Quarterly Journal of Economics 109, 465 - 490.

Bethencourt, C., Galasso, V., 2008. Political complements in the welfare state: Health care and social security. Journal of Public Economics 92, 609 - 632.

Borck, R., 2004. Stricter enforcement may increase tax evasion. European Journal of Political Economy 20, 725-737.

Borck, R., 2009. Voting on redistribution with tax evasion. Social Choice Welfare $32,439-454$. 
Bredemeier, C., 2013. Imperfect information and the meltzer-richard hypothesis. Public Choice, forthcoming.

Conde-Ruiz, J. I., Galasso, V., 2003. Early retirement. Review of Economic Dynamics 6, 12-36.

Conde-Ruiz, J. I., Galasso, V., 2005. Positive arithmetic of the welfare state. Journal of Public Economics 89, 933-955.

DeFreitas, J., 2012. Inequality, the politics of redistribution and the tax mix. Public Choice 151, $611-630$.

Esteban, J., Gradin, C., Ray, D., 2007. An extension of a measure of polarization, with an application to the income distribution of five Oecd countries. The Journal of Economic Inequality 5, 1-19.

Evans, C., 2003. Studying the studies: An overview of recent research into taxation operating costs. eJournal of Tax Research 1, 64-92.

Georgiadis, A., Manning, A., 2012. Spend it like Beckham? Inequality and redistribution in the UK. Public Choice 151, $537-563$.

Gouveia, M., Masia, N. A., 1998. Does the median voter model explain the size of government? Evidence from the states. Public Choice 97, 159-177.

Gravelle, J. G., 2013. Tax havens: International tax avoidance and evasion. CRS Report for Congress, Prepared for Members and Committees of Congress.

Kenworthy, L., McCall, L., 2008. Inequality, public opinion and redistribution. Socio-Economic Review 6, $35-68$.

Lang, O., Noehrbaß, K.-H., Stahl, K., 1997. On income tax avoidance: the case of Germany. Journal of Public Economics 66, 327 - 347 .

Meltzer, A. H., Richard, S. F., 1981. A rational theory of the size of government. Journal of Political Economics 89, 914 - 927.

Meltzer, A. H., Richard, S. F., 1983. Tests of a rational theory of the size of government. Public Choice 41, $403-418$.

Milasi, S., 2013. Top income shares and budget deficits. CEIS Working Paper No. 249. 
OECD, 2013. Tax administration 2013: Comparative information on oecd and other advanced and emerging economies. OECD Publishing http://dx.doi.org/10.1787/9789264200814-en.

Persson, T., Tabellini, G., 1994. Is inequality harmful for growth? American Economic Review 84, $600-621$.

Persson, T., Tabellini, G., 2000. Political Economics. Explaining Economic Policy. The MIT Press.

Rodriguez, F., 1999. Does distributional skewness lead to redistribution? Evidence from the United States. Economics and Politics 11, 171-199.

Roine, J., 2006. The political economics of not paying taxes. Public Choice 126, $107-134$

Sandford, C., Godwin, M., Hardwick, P., 1989. Administrative and Compliance Costs of Taxation. Fiscal Publications, Bath.

Sandmo, A., 1981. Income tax evasion, labour supply, and the equity-efficiency tradeoff. Journal of Public Economics 16, 265 - 288.

Shepsle, K. A., 1979. Institutional arrangements and equilibrium in multidimensional voting models. American Journal of Political Science 23, 27-59.

Slemrod, J., 1990. Optimal taxation and optimal tax systems. Journal of Economic Perspectives 4, $157-178$.

Slemrod, J., 1994. Fixing the leak in Okun's bucket optimal tax progressivity when avoidance can be controlled. Journal of Public Economics 55, 41 - 51.

Slemrod, J., 2001. A general model of the behavioral response to taxation. International Tax and Public Finance 8, 119 - 128.

Slemrod, J., 2007. Cheating ourselves: the economics of tax evasion. Journal of Economic Perspectives 21, 25-48.

Slemrod, J., Yitzhaki, S., 1987. The optimal size of a tax collection agency. The Scandinavian Journal of Economics 89, 183 - 192.

Slemrod, J., Yitzhaki, S., 2002. Tax avoidance, evasion, and administration. Handbook of Public Economics 3, 1425-1469. 
Traxler, C., 2009. Voting over taxes: the case of tax evasion. Public Choice 140, $43-58$.

Traxler, C., 2012. Majority voting and the welfare implications of tax avoidance. Journal of Public Economics 96, 1 - 9 .

\section{Appendix}

\section{Proof of Lemma 1:}

For a type- $y$ taxpayer, the first derivative of her indirect utility function, Eq. (6), w.r.t. $\tau$ is

$$
F O C_{\tau}^{y}=-\frac{y}{\gamma}\left(\frac{\tau}{\kappa(1+\gamma) e^{1+\delta}}\right)^{1 / \gamma}+(\widetilde{y}-y)\left(1-\frac{1+\gamma}{\gamma}\left(\frac{\tau}{\kappa(1+\gamma) e^{1+\delta}}\right)^{1 / \gamma}\right)
$$

Thus, the second derivative w.r.t. $\tau$ is

$$
S O C_{\tau}^{y}=-\left(\frac{1}{\kappa(1+\gamma) e^{1+\delta}}\right)^{1 / \gamma}\left[\frac{y}{1+\gamma}+(\widetilde{y}-y)\right]
$$

Notice that $S O C_{\tau}^{y}$ is always negative if $y<\left(\frac{1+\gamma}{\gamma}\right) \widetilde{y}$ and therefore, preferences are single peaked in the $\tau$ dimension.

Similarly, the first derivative of her indirect utility function w.r.t. $e$ is

$$
F O C_{e}^{y}=\left(\frac{1+\delta}{\gamma}\right)\left(\frac{\tau}{1+\gamma}\right)^{(1+\gamma) / \gamma} \frac{[y+(\widetilde{y}-y)(1+\gamma)]}{\kappa^{1 / \gamma}} e^{-\left(\frac{1+\gamma+\delta}{\gamma}\right)}-e^{\eta}
$$

and the $S O C_{e}^{y}$ is

$S O C_{e}^{y}=-\frac{(1+\gamma+\delta)(1+\delta)}{\gamma^{2}}\left(\frac{\tau}{1+\gamma}\right)^{(1+\gamma) / \gamma} \frac{[y+(\widetilde{y}-y)(1+\gamma)]}{\kappa^{1 / \gamma}} e^{-\left(\frac{1+2 \gamma+\delta}{\gamma}\right)}-\eta e^{\eta-1}$

Since the last term is always negative, $S O C_{e}^{y}$ is negative if $y<\left(\frac{1+\gamma}{\gamma}\right) \widetilde{y}$. This condition guarantees that preferences are single peaked in the $e$ dimension.

\section{Proof of Lemma 2:}

In the proof of Lemma 1 we have calculated the first derivative w.r.t. $\tau$ for a 
type- $y$ taxpayer. Equating $F O C_{\tau}^{y}=0$ yields

$$
\begin{aligned}
0 & =-\frac{y}{\gamma}\left(\frac{\tau}{\kappa(1+\gamma) e^{1+\delta}}\right)^{1 / \gamma}+(\widetilde{y}-y)\left(1-\frac{1+\gamma}{\gamma}\left(\frac{\tau}{\kappa(1+\gamma) e^{1+\delta}}\right)^{1 / \gamma}(18)\right. \\
(\widetilde{y}-y) & =\left[\frac{y}{\gamma}\left(\frac{1}{\kappa(1+\gamma) e^{1+\delta}}\right)^{1 / \gamma}+(\widetilde{y}-y) \frac{1+\gamma}{\gamma}\left(\frac{1}{\kappa(1+\gamma) e^{1+\delta}}\right)^{1 / \gamma}\right] \tau^{1 /{ }^{\prime}(19)} \\
(\widetilde{y}-y) & =\left[\left(\frac{1+\gamma}{\gamma}\right) \widetilde{y}-y\right]\left(\frac{1}{\kappa(1+\gamma) e^{1+\delta}}\right)^{1 / \gamma} \tau^{1 / \gamma}
\end{aligned}
$$

and thus

$$
\tau=\kappa(1+\gamma) e^{1+\delta}\left(\frac{\widetilde{y}-y}{\left(\frac{1+\gamma}{\gamma}\right) \widetilde{y}-y}\right)^{\gamma}
$$

Therefore,

$$
\tau(e)=\max \left\{0, \kappa(1+\gamma) e^{1+\delta}\left(\frac{\widetilde{y}-y}{\left(\frac{1+\gamma}{\gamma}\right) \widetilde{y}-y}\right)^{\gamma}\right\}
$$

If $\widetilde{y}>y$, it is easy to see that $\tau(e)>0$ and

$$
\begin{aligned}
\frac{\partial \tau(e)}{\partial y} & =-\frac{\tilde{y} \tau(e)}{\gamma(\widetilde{y}-y)\left(\left(\frac{1+\gamma}{\gamma}\right) \widetilde{y}-y\right)}<0 \\
\frac{\partial \tau(e)}{\partial e} & =(1+\delta) \frac{\tau(e)}{e}>0
\end{aligned}
$$

\section{Proof of Lemma 3:}

From the proof of Lemma 1 we have calculated the first first derivative w.r.t. $e$ for a type- $y$ taxpayer. If we equates $F O C_{e}^{y}=0$ we obtain that

$$
\begin{aligned}
0 & =\left(\frac{1+\delta}{\gamma}\right)\left(\frac{\tau}{1+\gamma}\right)^{(1+\gamma) / \gamma} \frac{[y+(\widetilde{y}-y)(1+\gamma)]}{\kappa^{1 / \gamma}} e^{-\left(\frac{1+\gamma+\delta}{\gamma}\right)}-e^{\eta} \\
e^{\eta+\left(\frac{1+\gamma+\delta}{\gamma}\right)} & =\left(\frac{1+\delta}{\gamma}\right)\left(\frac{\tau}{1+\gamma}\right)^{(1+\gamma) / \gamma} \frac{[y+(\widetilde{y}-y)(1+\gamma)]}{\kappa^{1 / \gamma}} \\
e & =\left[\left(\frac{1+\delta}{1+\gamma}\right)\left(\frac{\tau^{1+\gamma}}{\kappa(1+\gamma)}\right)^{1 / \gamma}\left(\left(\frac{1+\gamma}{\gamma}\right) \widetilde{y}-y\right)\right]^{\frac{\gamma}{1+\gamma(1+\eta)+\delta}}
\end{aligned}
$$


It is easy to see that $e>0 \forall y$ since $y \in\left(\underline{y},\left(\frac{1+\gamma}{\gamma}\right) \widetilde{y}\right)$. Also, we have

$$
\begin{aligned}
\frac{\partial e(\tau)}{\partial y} & =-\left(\frac{\gamma}{1+\gamma(1+\eta)+\delta}\right) \frac{e(\tau)}{\left(\left(\frac{1+\gamma}{\gamma}\right) \widetilde{y}-y\right)}<0 \\
\frac{\partial e(\tau)}{\partial \tau} & =\left(\frac{1+\gamma}{1+\gamma(1+\eta)+\delta}\right) \frac{e(\tau)}{\tau}>0
\end{aligned}
$$

\section{Proof of Proposition 1:}

Case $(A)$ is trivial since $\tau(e)=0 \forall y>\widetilde{y}$ and $e(\tau=0)=0$.

Case $(B)$ : The most preferred tax rate and enforcement level by the median voter are defined by Eqs. (7) and (8) respectively. To simplify calculations, we rewrite them as follows:

$$
\begin{aligned}
\tau & =e^{1+\delta} m_{2} \\
e & =\left[\tau^{\frac{1+\gamma}{\gamma}} m_{1}\right]^{\frac{\gamma}{1+\gamma(1+\eta)+\delta}}
\end{aligned}
$$

where

$$
\begin{aligned}
& m_{1}=\left(\frac{1+\delta}{1+\gamma}\right)\left(\frac{1}{\kappa(1+\gamma)}\right)^{1 / \gamma}\left(\left(\frac{1+\gamma}{\gamma}\right) \widetilde{y}-y_{m}\right) \\
& m_{2}=\kappa(1+\gamma)\left(\frac{\widetilde{y}-y_{m}}{\left(\frac{1+\gamma}{\gamma}\right) \widetilde{y}-y_{m}}\right)^{\gamma}
\end{aligned}
$$

Then, substituting $\tau$ at $e(\tau)$ gives

$$
\begin{aligned}
e & =\left[e^{\frac{(1+\delta)(1+\gamma)}{\gamma}} m_{2}^{\frac{(1+\gamma)}{\gamma}} m_{1}\right]^{\frac{\gamma}{1+\gamma(1+\eta)+\delta}} \\
\Leftrightarrow e^{*} & =\left(m_{1} m_{2}^{\frac{1+\gamma}{\gamma}}\right)^{\frac{1}{\eta-\delta}}
\end{aligned}
$$

which in turn implies

$$
\tau^{*}=\left(m_{1} m_{2}^{\frac{1+\gamma}{\gamma}}\right)^{\frac{(1+\delta)}{\eta-\delta}} m_{2}=\left(\left(m_{1} m_{2}^{\frac{1}{\gamma}}\right)^{(1+\delta)} m_{2}^{1+\eta}\right)^{\frac{1}{\eta-\delta}}
$$

\section{Proof of Proposition 2:}


Note that both $m_{1}$ and $m_{2}$ are decreasing in $y_{m}$

$$
\begin{aligned}
& \frac{\partial m_{1}}{\partial y_{m}}=-\left(\frac{1+\delta}{1+\gamma}\right)\left(\frac{1}{\kappa(1+\gamma)}\right)^{1 / \gamma}<0 \\
& \frac{\partial m_{2}}{\partial y_{m}}=-\frac{\kappa(1+\gamma) \widetilde{y}}{\left(\left(\frac{1+\gamma}{\gamma}\right) \widetilde{y}-y_{m}\right)^{2}}\left(\frac{\widetilde{y}-y_{m}}{\left(\frac{1+\gamma}{\gamma}\right) \tilde{y}-y_{m}}\right)^{\gamma-1}<0
\end{aligned}
$$

We then have

$$
\frac{\partial e^{*}}{\partial y_{m}}=\frac{\left(m_{1} m_{2}^{\frac{1+\gamma}{\gamma}}\right)^{\frac{1}{\eta-\delta}-1}}{\eta-\delta} \frac{\partial\left(m_{1} m_{2}^{\frac{1+\gamma}{\gamma}}\right)}{\partial y_{m}} \gtrless 0 \Leftrightarrow \eta \lessgtr \delta
$$

and similarly

$$
\frac{\partial \tau^{*}}{\partial y_{m}}=\frac{\left(\left(m_{1} m_{2}^{\frac{1}{\gamma}}\right)^{(1+\delta)} m_{2}^{1+\eta}\right)^{\frac{1}{\eta-\delta}-1}}{\eta-\delta} \frac{\partial\left(\left(m_{1} m_{2}^{\frac{1}{\gamma}}\right)^{(1+\delta)} m_{2}^{1+\eta}\right)}{\partial y_{m}} \gtrless 0 \Leftrightarrow \eta \lessgtr \delta
$$

